\title{
Systems on Top of Nasal Cannula Improve Oxygen Delivery in Patients with COVID-19: a Randomized Controlled Trial
}

\author{
William Poncin, $P h D^{1,2,3}$ (D) , Lia Baudet, $P T^{3}$, Frederic Braem, $P T^{3}$, \\ Gregory Reychler, $P h D^{1,2,3}$, Frédéric Duprez, $P h D^{4,5}$, Giuseppe Liistro, $P h D^{1,2}$, \\ Leila Belkhir, PhD 6,7 , Jean Cyr Yombi, MD 6 , and Julien De Greef, $M D^{6,7}$
}

\begin{abstract}
'Institut de recherche expérimentale et clinique (IREC), pôle de Pneumologie, ORL et Dermatologie, Université Catholique de Louvain, Avenue Hippocrate 55, Brussels, Belgium; ${ }^{2}$ Service de Pneumologie, Cliniques universitaires Saint-Luc, Avenue Hippocrate 10, Brussels, Belgium; ${ }^{3}$ Secteur de Kinésithérapie et Ergothérapie, Cliniques universitaires Saint-Luc, Avenue Hippocrate 10, Brussels, Belgium; ' Unité de Soins Intensifs, Clinique Epicura, 63 rue de Mons 7301 Hornu, Boussu, Belgium; 'Laboratory of Respiratory Physiology, Condorcet, Tournai, Belgium; 'Service de Médecine Interne et Maladies Infectieuses, Cliniques universitaires Saint-Luc, Avenue Hippocrate 10, Brussels, Belgium; ' Louvain Centre for Toxicology and Applied Pharmacology, Institut de recherche expérimentale et clinique (IREC), Université Catholique de Louvain, Avenue Hippocrate 55, Brussels, Belgium.
\end{abstract}

BACKGROUND: Treating hypoxemia while meeting the soaring demands of oxygen can be a challenge during the COVID-19 pandemic.

OBJECTIVE: To determine the efficacy of the surgical facemask and the double-trunk mask on top of the lowflow oxygen nasal cannula on arterial partial pressure of oxygen $\left(\mathrm{PaO}_{2}\right)$ in hypoxemic COVID-19 patients.

DESIGN: Randomized controlled trial.

PARTICIPANTS: Hospitalized adults with COVID-19 and hypoxemia treated with the low-flow nasal cannula were enrolled between November 13, 2020, and March 05, 2021.

INTERVENTIONS: Patients were randomized in a $1: 1: 1$ ratio to receive either the nasal cannula alone (control) or the nasal cannula covered by the surgical facemask or the double-trunk mask. Arterial blood gases were collected at baseline and $30 \mathrm{~min}$ after the use of each system. The oxygen output was adapted afterwards to retrieve the baseline pulse oxygen saturation. The final oxygen output value was recorded after another 30-min period.

MAIN MEASURES: The primary outcome was the absolute change in $\mathrm{PaO}_{2}$. Secondary outcomes included changes in oxygen output, arterial partial pressure of carbon dioxide $\left(\mathrm{PaCO}_{2}\right)$, vital parameters, and breathlessness.

KEY RESULTS: Arterial blood samples were successfully collected in 24/27 (8 per group) randomized patients. Compared to the nasal cannula alone, $\mathrm{PaO}_{2}$ increased with the surgical facemask (mean change: $20 \mathrm{mmHg}, 95 \% \mathrm{CI}$ : 0.7-38.8; $P=.04$ ) and with the double-trunk mask (mean change: $40 \mathrm{mmHg}$; 95\% CI: 21-59; $P<.001$ ). Oxygen output was reduced when adding the surgical facemask (median reduction: $1.5 \mathrm{~L} / \mathrm{min}$ [95\% CI: 0.5-4.5], $P<.001$ ) or the double-trunk mask (median reduction: $3.3 \mathrm{~L} / \mathrm{min}$ [95\% CI: 2-5], $P<.001)$. The double-trunk mask was associated with $\mathrm{PaCO}_{2}$ increase of $2.4 \mathrm{mmHg}$ ([95\% CI: 0-4.7], $P=$.049). Neither mask influenced vital parameters or breathlessness.

Received November 19, 2021

Accepted January 14, 2022

Published online February 8, 2022
CONCLUSIONS: The addition of the surgical facemask or the double-trunk mask above the nasal cannula improves arterial oxygenation and reduces oxygen consumption.

KEY WORDS: coronavirus disease 2019; hypoxemia; oxygen therapy; double-trunk mask; surgical mask.

$\mathrm{J}$ Gen Intern Med 37(5):1226-32

DOI: $10.1007 / \mathrm{s} 11606-022-07419-2$

(c) The Author(s) under exclusive licence to Society of General Internal Medicine 2022

\section{INTRODUCTION}

Hypoxemia is a typical feature of the coronavirus disease 2019 (COVID-19) caused by the severe acute respiratory syndrome coronavirus 2 (SARS-CoV-2) infection. An early epidemiological study indicated that $19 \%$ of infected patients develop a severe or critical pneumonia and present a pulse oxygen saturation $\leq 93 \%$ at rest. ${ }^{1}$ While $5 \%$ of patients will necessitate intensive care, most hospitalized COVID-19 patients will require supplemental oxygen therapy ${ }^{2,3}$ that can be managed on a regular ward. ${ }^{4}$

Low-flow nasal cannulas are the most commonly used oxygen delivery systems to treat mild to moderate hypoxemia. 5 Those open systems of supplementation are characterized by a high amount of leaking air around the oxygen source. The high respiratory rate observed in COVID-19 patients $^{2,3,7,8}$ will further decrease the fraction of oxygen delivered into the lungs. To meet the patient's oxygen needs, the oxygen output must be increased. However, higher flows of dry gas into the nasopharyngeal passage are uncomfortable and increase the risks of mucosa dryness, nasal resistance, ${ }^{9}$ and epistaxis, ${ }^{10}$ which reduce compliance to therapy. In addition, the COVID-19 pandemic has exposed countries to a sudden spurt in oxygen demand, overwhelming the deficient oxygen supply systems of unprepared regions and threatening patient survival. ${ }^{11}$ Oxygen distribution and delivery are particularly compromised in low- and middle-income countries. $^{12-14}$ Some settings of high-income countries have 
also experienced shortages of oxygen, such as nursing homes and ambulatory care. ${ }^{15}$

Because of the above-mentioned concerns, there is an imperative need to improve the performance of patients' oxygen delivery with easy-to-perform procedures with the objective of reducing oxygen consumption. For instance, studies showed that the double-trunk mask, an aerosol mask in which two tubes have been fixed in each of the side holes, had the potential to improve the performance of the nasal cannula ${ }^{16-}$

18 (Figure E1 and online data supplement). More recently, Montiel et al. have observed that the placement of a surgical facemask in patients already treated with a high-flow nasal cannula improved their oxygenation without relevant side effects. ${ }^{19}$ However, there is no study assessing the effect of the surgical facemask above the low-flow nasal cannula, nor data comparing the relative effectiveness of these two systems. The objective of this study was thus to compare the relative impact of the surgical facemask and the double-trunk mask in improving blood oxygenation in hospitalized COVID-19 patients already treated with the low-flow nasal cannula. We also assessed their relative impact in saving oxygen supplies.

\section{METHODS}

\section{Study Design}

All adult patients hospitalized between November 13, 2020, and March 05, 2021, at Cliniques universitaires Saint-Luc, Brussels, Belgium, with hypoxemic COVID-19 pneumonia requiring low-flow oxygen therapy between 3 and $7 \mathrm{~L} / \mathrm{min}$ with a nasal cannula to maintain peripheral capillary oxygen saturation $\left(\mathrm{SpO}_{2}\right)$ between 92 and $96 \%$ were invited to participate in this trial. According to our routine practice, patients undergo supplemental oxygen flow titration at least twice daily by physicians not involved in the study to achieve a target $\mathrm{SpO}_{2}$ of $94 \%$ at the lowest output. Exclusion criteria were chronic respiratory diseases, language barriers, confusion, altered consciousness, and arterial puncture contraindications.

Patients who provided written informed consent were placed in a semi-recumbent position and instructed to remain lying over the 60-min-long experiment with continuous pulse oximeter reading. Oxygen flow was fixed (unless clinical deterioration) during the first half of the experiment. Arterial blood gas was taken at the onset of the experiment. Then, the patients were randomized to continue oxygen therapy via the nasal cannula alone (control group), or to receive oxygen via the nasal cannula covered by either the surgical facemask or the double-trunk mask. A second arterial blood gas sample was collected 30 min later.

If the pulse oximeter reading differed between the start and the end of the first 30-min period, the oxygen flow was adapted for the second half of the experiment to retrieve the baseline $\mathrm{SpO}_{2}$ following a predefined protocol (detailed in the online supplement). The final oxygen output was recorded after the second 30-min period. All along the process, correct placement of the masks was verified and patients received no instructions regarding nasal or mouth breathing.

The study was approved by the local ethics committee (B4032020000009) and is registered in ClinicalTrials.gov (NCT04629989).

\section{Outcomes}

The primary outcome was the arterial partial pressure of oxygen $\left(\mathrm{PaO}_{2}\right)$ change after $30 \mathrm{~min}$. Secondary outcomes were changes in arterial blood gases (oxygen saturation $\left[\mathrm{SaO}_{2}\right]$, partial pressure of carbon dioxide $\left.\left[\mathrm{PaCO}_{2}\right], \mathrm{pH}\right)$ and vital parameters (temperature, respiratory rate, heart rate, blood pressure) between baseline and the end of the first 30min period, and changes in oxygen output and breathlessness between baseline and end of the experiment (i.e., after 60 min). Details are provided in the online data supplement.

\section{Statistical Analysis}

Normality of data was verified with the Shapiro-Wilk test. Data are presented as mean \pm standard deviation (SD) or median and interquartile range (IQR) as appropriate. Paired $t$ test or Wilcoxon test was applied for within-group changes between the different time points. Between-group differences were compared using one-way analysis of variance or Kruskal-Wallis test. Bonferroni correction was applied for pairwise comparisons. The natural variability of repeated $\mathrm{PaO}_{2}$ measurements within individuals was represented by the coefficient of repeatability and was calculated as $1.96 \times \mathrm{SD}$ of $\mathrm{PaO}_{2}$ differences in the control group. It reflects the $95 \%$ range of physiological and technical variability in $\mathrm{PaO}_{2}$. A $\mathrm{PaO}_{2}$ change greater than the coefficient of repeatability was considered as physiologically meaningful. Correlations were calculated via Pearson $r$ coefficient. All tests were two-sided and $P$ values $\leq .05$ were considered significant. Secondary outcomes were analyzed as exploratory analyses. Statistical analyses were performed using SPSS v27 (IBM, New York, USA).

Randomization procedure, sample size, and power calculation are described in the supplements.

\section{RESULTS}

\section{Participants}

Of 34 consecutive eligible patients who were proposed trial inclusion, 27 agreed to be enrolled and were randomized. Owing to procedural failure in obtaining two arterial blood samples in 3 participants, analyses were performed for the 24 patients ( 8 per group) who completed the entire study procedure (study flowchart in Fig. 1). The mean (SD) age of participants was $67(10)$ years; $18(75 \%)$ were males with a body mass index of $28.3(5.4) \mathrm{kg} / \mathrm{m}^{2}$. Table 1 details baseline characteristics for the entire cohort as well as for each group. There was no difference in any baseline parameters between groups. The mean delivered oxygen flow at inclusion was 4.7 


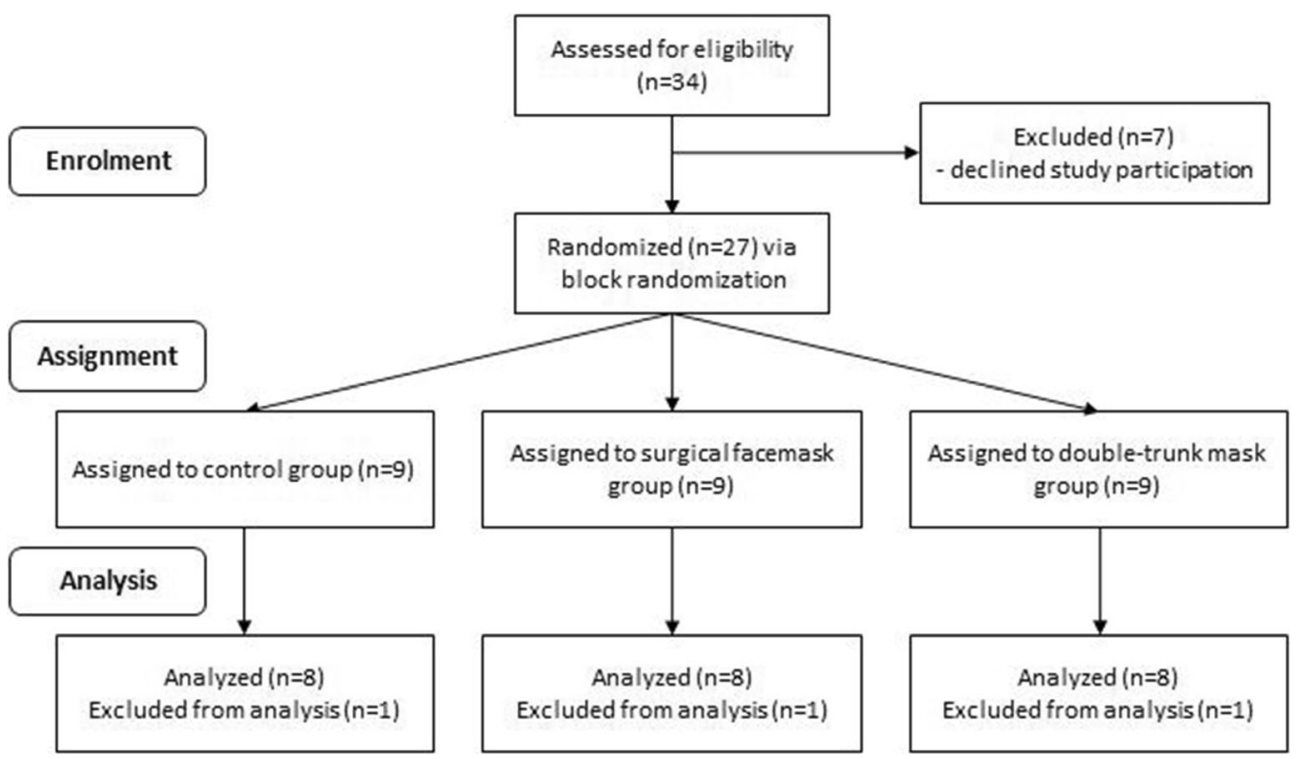

Figure 1 Study flowchart.

(1.4) $\mathrm{L} / \mathrm{min}$. The median (IQR) $\mathrm{SpO}_{2}$ measured at this flow rate was $94 \%$ (92-95).

\section{Primary Outcome}

Compared to the nasal cannula alone, $\mathrm{PaO}_{2}$ increased with the surgical facemask (mean change: $20 \mathrm{mmHg}$, 95\% CI: $0.7-38.8 ; P=.04$ ) and with the double-trunk mask (mean change: $40 \mathrm{mmHg}$; 95\% CI: $21-59 ; P<.001)$. The doubletrunk mask outperformed the surgical facemask on arterial oxygenation (mean change: $20.5 \mathrm{mmHg}$, 95\% CI: 1.5-39.5, $P=$.032) (Fig. 2, Table 2).

\section{Secondary Outcomes}

Adding the systems on top of the nasal cannula resulted in an average (SD) oxygen output reduction of $40 \%$ (21) with the surgical facemask (median reduction: $1.5 \mathrm{~L} / \mathrm{min}$ [95\% CI: $0.5-$ 4.5], $P<.001)$ and $73 \%$ (7) with the double-trunk mask (median reduction: $3.3 \mathrm{~L} / \mathrm{min}$ [95\% CI: $2-5], P<.001)$. The difference between both systems was not statistically significant (Fig. 2, Table 2).

Compared to the control group, the $\mathrm{SaO}_{2}$ significantly improved with each mask. There was, however, no significant difference on $\mathrm{SaO}_{2}$ between those two systems (Table 2). The double-trunk mask was associated with an increase in arterial partial pressure of carbon dioxide $\left(\mathrm{PaCO}_{2}\right)$ of $2.4 \mathrm{mmHg}(95 \%$ CI: $0-4.7, P=.049)$ and a decrease in $\mathrm{pH}$ of $0.02(95 \% \mathrm{CI}$ : $0.00-0.03, P=.024)$. The surgical facemask showed no impact on $\mathrm{PaCO}_{2}$. Neither of the two masks influenced vital parameters (except $\mathrm{SpO}_{2}$ which followed the pattern of $\mathrm{SaO}_{2}$ change) nor breathlessness (Table 2).

There was a significant positive relationship between the baseline oxygen output and the $\mathrm{PaO}_{2}$ change with the surgical facemask ( $r=0.83$ [95\% CI: $0.29-0.97$ ], $P=.011$ ), but not with the double-trunk mask $(r=0.04$ [95\% CI: -0.69 to 0.72 ,
$P=.93)$. The $\mathrm{PaO}_{2}$ difference elicited by the surgical facemask exceeded the coefficient of repeatability $(15.2 \mathrm{mmHg})$ only when baseline oxygen flows were $\geq 5 \mathrm{~L} / \mathrm{min}$. There was a systematic $\mathrm{PaO}_{2}$ improvement outside the coefficient of repeatability with the double-trunk mask, regardless of the baseline oxygen output (Fig. 3).

Finally, there was a significant negative relationship between the $\mathrm{PaO}_{2}$ change and the relative oxygen output difference both with the surgical facemask $(r=-0.73$ [95\% CI: -0.95 to -0.06$], P=.039)$ and the doubletrunk mask ( $r=-0.73$ [95\% CI: -0.95 to -0.05$], P=.040)$.

\section{DISCUSSION}

This randomized controlled trial demonstrated that both the surgical and double-trunk masks improved arterial oxygenation in hypoxemic COVID-19 patients receiving low-flow oxygen nasal cannula therapy. Unlike the surgical facemask, the double-trunk mask had a systematic effect regardless of the baseline oxygen flow. In addition, for a set $\mathrm{SpO}_{2}$ target, the surgical facemask and the double-trunk mask enabled the reduction of the oxygen flow by $40 \%$ and $73 \%$, respectively, compared to the nasal cannula alone.

Our findings collected with the double-trunk mask are supported by other trials using the same mask or variant masks with tubes inserted on each side. ${ }^{17,20-22}$ More recently, we have shown that the double-trunk mask was able to preserve a target oxygenation level while reducing the oxygen output by more than $50 \%$ of the output required by conventional oxygen delivery systems. ${ }^{7}$ The oxygen-boosting effect of the doubletrunk mask is likely explained by its storing capacity. The addition of the double-trunk mask on the patient's face adds a static dead space of approximately $210 \mathrm{~mL}{ }^{16}$ Therefore, this mask acts as a reservoir which collects and stores nonconsumed oxygen during expiratory phases with nasal 
Table 1 Baseline Characteristics

\begin{tabular}{|c|c|c|c|c|c|}
\hline & Total $(n=24)$ & Control $(n=8)$ & SFM $(n=8)$ & DTM $(n=8)$ & $P$ value \\
\hline \multicolumn{6}{|l|}{ Demographics } \\
\hline Age, mean (SD), years & $67(10)$ & $64(5)$ & $66(10)$ & $71(14)$ & 0.407 \\
\hline Sex, no. males $(\%)$ & $18(75)$ & $6(75)$ & $8(100)$ & $4(50)$ & NA \\
\hline BMI, mean (SD), $\mathrm{kg} / \mathrm{m}^{2}$ & $28.3(5.4)$ & $26.6(3.5)$ & $26.8(2.6)$ & $31.6(7.6)$ & 0.110 \\
\hline \multicolumn{6}{|l|}{ Symptoms and disease severity } \\
\hline Symptom duration, median (IQR), days & $11(10-14)$ & $12.5(10-16)$ & $11.5(8.5-13)$ & $10.5(8.5-13)$ & 0.672 \\
\hline CRP level at admission, median (IQR), $\mathrm{mg} / \mathrm{L}$ & $79.4(49.7-121.2)$ & $61.4(31.8-104.1)$ & $76.4(50.8-210)$ & $85.9(71.4-118)$ & 0.468 \\
\hline CRP level at the study day, median (IQR), $\mathrm{mg} / \mathrm{L}$ & $59.6(19.6-96.5)$ & $26.2(13.6-69.4)$ & $85.8(39.6-129.1)$ & $60.9(19.8-128)$ & 0.170 \\
\hline Oxygen flow, mean (SD), L/min & $4.7(1.4)$ & $4.7(1.4)$ & $4.9(1.7)$ & $4.6(1.5)$ & 0.917 \\
\hline Breathlessness, median (IQR), 0-100 mm & $13(0-38)$ & $10(0-35)$ & $27(16-47)$ & $0(0-23)$ & 0.096 \\
\hline \multicolumn{6}{|l|}{ Arterial blood gases } \\
\hline $\mathrm{SaO}_{2}$, mean $(\mathrm{SD}), \%$ & $94.6(2.3)$ & $95.9(1.5)$ & $94.1(2.8)$ & $93.7(2.1)$ & 0.119 \\
\hline $\mathrm{PaO}_{2}$, mean (SD), mmHg & $71.5(10.1)$ & $76.5(10.7)$ & $70.9(10.5)$ & $67.1(7.7)$ & 0.176 \\
\hline $\mathrm{PaCO}_{2}$, mean (SD), mmHg & $33.9(3.3)$ & $35.6(2.9)$ & $33(3.3)$ & $33(3.4)$ & 0.195 \\
\hline $\mathrm{pH}$, mean (SD) & $7.45(0.04)$ & $7.47(0.04)$ & $7.44(0.04)$ & $7.45(0.04)$ & 0.457 \\
\hline \multicolumn{6}{|l|}{ Vital parameters } \\
\hline $\mathrm{SpO}_{2}$, median (IQR), \% & $94(92-95)$ & $94.5(94-95)$ & $93(92-95.5)$ & $93.5(92-95)$ & 0.293 \\
\hline Temperature, mean (SD), ${ }^{\circ} \mathrm{C}$ & $36.0(0.6)$ & $36.1(0.5)$ & $35.9(0.9)$ & $35.9(0.5)$ & 0.651 \\
\hline Respiratory rate, mean (SD), breaths/min & $24.8(5.9)$ & $24.6(5.3)$ & $26.5(5.0)$ & $23.3(7.5)$ & 0.569 \\
\hline Heart rate, mean (SD), beats/min & $74.6(11.9)$ & $75.5(9.8)$ & $76.5(14)$ & 71.9 (12.7) & 0.735 \\
\hline Systolic blood pressure, mean (SD), $\mathrm{mmHg}$ & 130 (19) & $130(16)$ & $132(27)$ & $129(15)$ & 0.952 \\
\hline Diastolic blood pressure, mean (SD), $\mathrm{mmHg}$ & $73(12)$ & $76(10)$ & $71(15)$ & $72(9)$ & 0.689 \\
\hline
\end{tabular}

Abbreviations: BMI body mass index, $\mathrm{CRP}$ C-reactive protein, $\mathrm{PaCO}_{2}$ arterial partial pressure of carbon dioxide, $\mathrm{PaO}_{2}$ arterial partial pressure of oxygen, $\mathrm{SaO}_{2}$ arterial oxygen saturation, $\mathrm{SpO}_{2}$ pulse oxygen saturation

cannula oxygen therapy. During subsequent inspiratory phases, the gas from this reservoir is first inspired before inhaling room air, thereby reducing air entrainment and increasing inspired oxygen concentration.
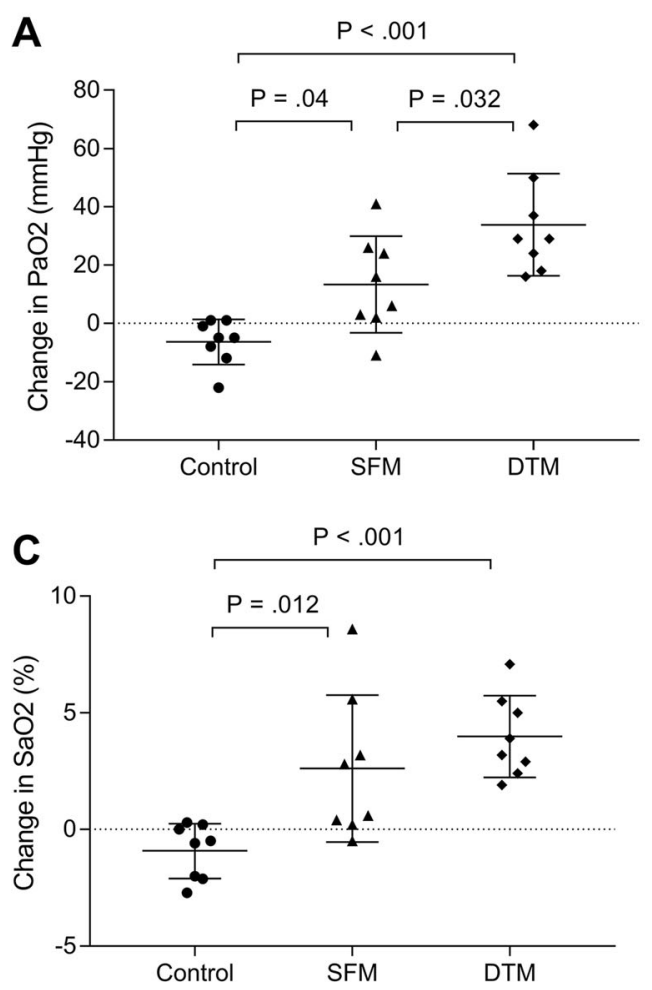

The large dead space volume associated with the doubletrunk mask could be a subject of concern because of potential $\mathrm{CO}_{2}$ rebreathing. Nevertheless, the $\mathrm{PaCO}_{2}$ increase when adding this mask was mild and of limited clinical significance as it
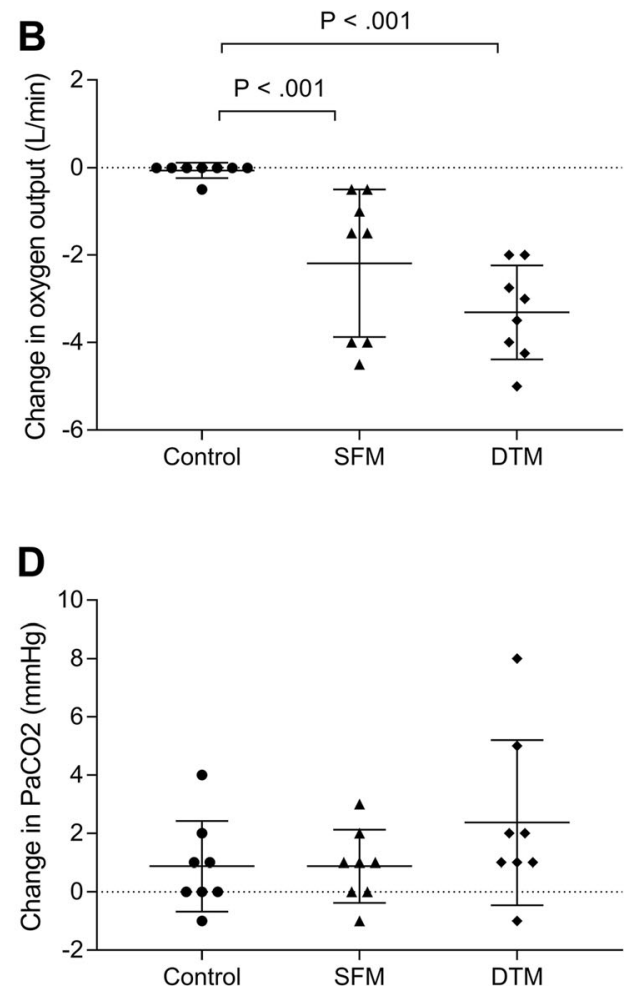

Figure 2 Changes in blood gas outcomes and oxygen output with and without the surgical and the double-trunk masks. The figure shows the difference in arterial partial pressure of oxygen (A), oxygen output (B), arterial oxygen saturation (C), and arterial partial pressure of carbon dioxide (D) before and $30 \mathrm{~min}$ after wearing either the nasal cannula alone (control, circles) or the nasal cannula covered by the surgical facemask (triangles) or the double-trunk mask (diamonds). Error bars indicate mean and standard deviation. Abbreviations: SFM, surgical facemask; DTM, double-trunk mask. 


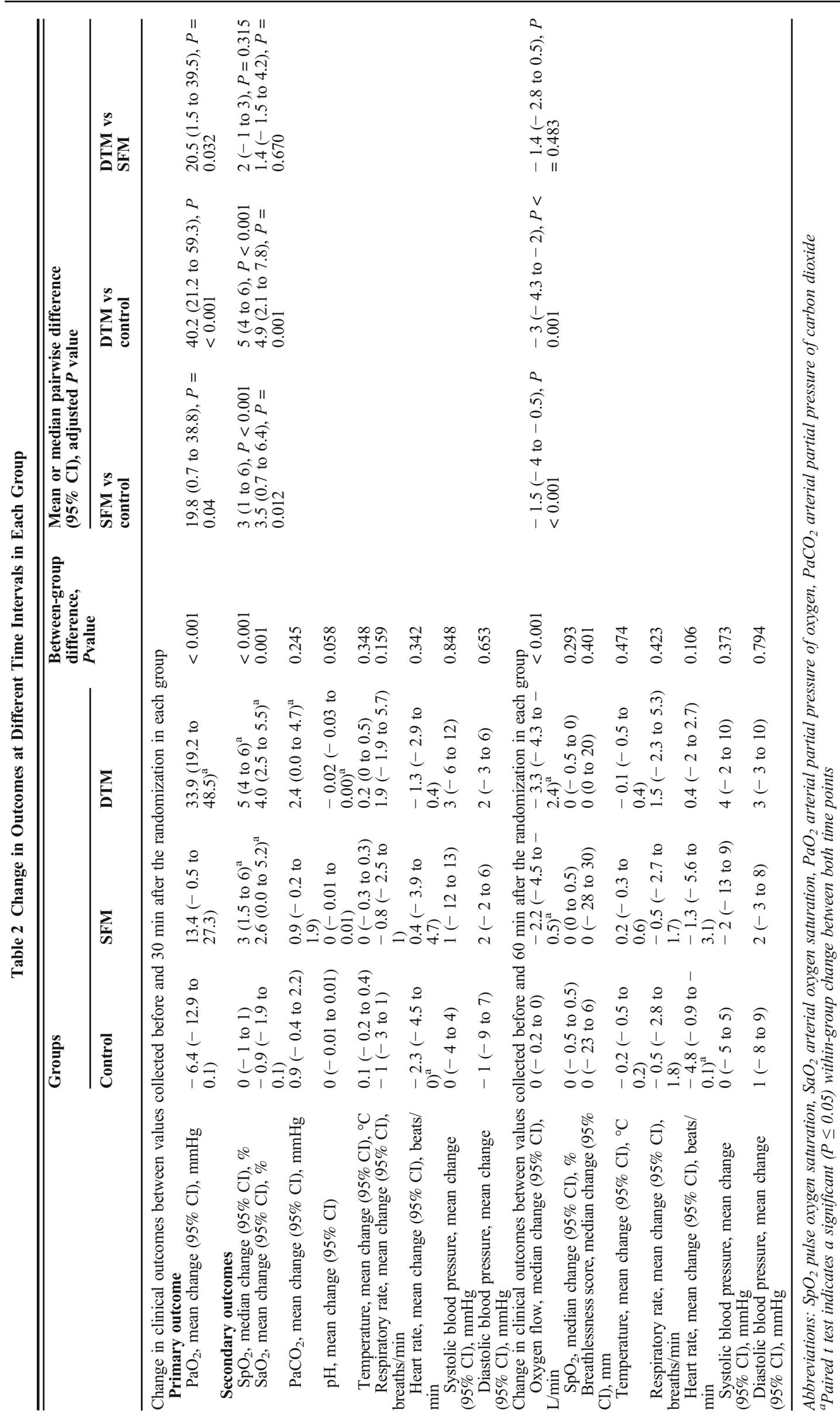




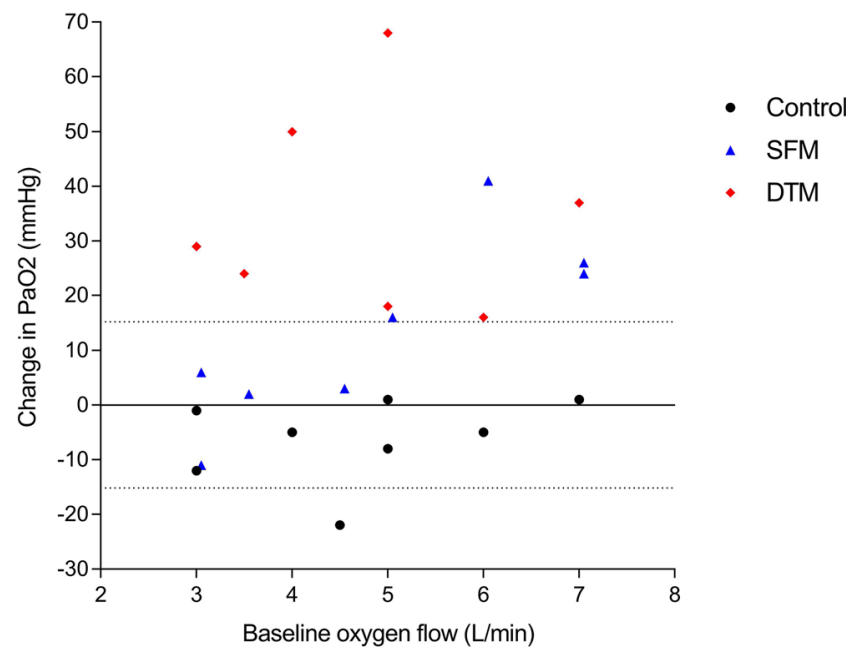

Figure 3 Individual change in arterial partial pressure of oxygen in relation to the baseline oxygen output. Individual changes in the control group (nasal cannula alone) are displayed as circles, nasal cannula with surgical facemask as triangles, and nasal cannula with double-trunk mask as diamonds. The middle solid line represents the null difference and the dotted lines the upper and lower limits of the coefficient of repeatability of arterial oxygen difference calculated in the control group $\left(1.96 \times \mathrm{SD}\right.$ of $\mathrm{PaO}_{2}$ differences), respectively. Abbreviations: SFM, surgical facemask; DTM, double-trunk mask.

did not translate into hypercapnia or blood acidosis, confirming previous findings. ${ }^{7}$ Instead, respiratory alkalosis was mitigated in patients with COVID-19 pneumonia where hypocapnic hypoxemia is a typical feature. ${ }^{8}$ Moreover, the patients did not report any change in their sensation of shortness of breath when the double-trunk mask was added. Most likely, these findings are explained by the facemask leaks and the streaming effect of gas through the system. The latter phenomenon is the result of the continuous oxygen flow beneath the mask through the nasal cannula, thereby reducing the dynamic dead space volume. ${ }^{23-25}$ It should be highlighted that we excluded patients with chronic pulmonary diseases in whom the safety, tolerance, and efficacy of the double-trunk mask has not been tested.

Interestingly, the surgical facemask placed over the nasal cannula also improved arterial oxygenation, albeit to a lesser magnitude than the double-trunk mask. These findings could also be explained by an increased oxygen concentration in the dead space created between the face and the mask. ${ }^{19}$ However, the magnitude of individual responses was variable, with only $50 \%$ of our participants exceeding the natural variability of consecutive $\mathrm{PaO}_{2}$ measurements. Based on Figure 3, it is tempting to speculate that a minimal baseline oxygen flow must be achieved to elicit a sensible increase in oxygen concentration in the mask dead space and, thus, in the patient's blood oxygen level. Below this threshold, the oxygen filling of the mask dead space may be insufficient to trigger a sensible effect on oxygenation beyond the natural $\mathrm{PaO}_{2}$ variability. However, this hypothesis must be interpreted with caution because of our small sample size. In addition, this speculation conflicts with the study of Montiel et al. who showed that the surgical facemask on top of the high-flow nasal cannula set at $60 \mathrm{~L} / \mathrm{min}$ also generated heterogeneous inter-individual responses. ${ }^{19}$

Another explanation would be that the surgical facemask promoted nasal breathing. Although we did not provide any instruction regarding nasal or mouth breathing, the addition of a facemask in mouth breathers may have elicited facial thermal discomfort. Indeed, mouth breathing is associated with a higher heat loss than nasal breathing. ${ }^{26}$ This heat loss is retained in the microenvironment created by the surgical facemask (i.e., dead space) which is acknowledged to generate discomfort. ${ }^{26} \mathrm{We}$ therefore speculate that the surgical facemask favored nasal breathing in our participants which, in turn, improved the oxygen uptake through the nasal cannula. Furthermore, compared to oral breathing, nasal breathing improves ventilation/ perfusion matching. ${ }^{27}$ Indeed, human paranasal sinuses produce nitric oxide that diffuses into the bronchial tree where it induces locally bronchodilation and vasodilation. ${ }^{27}$ Of note, Montiel et al. often observed spontaneous opened-mouth breathing in their cohort under a high-flow nasal cannula without a facemask. ${ }^{19}$ Unfortunately, we did not collate the proportion of mouth and nose breathers at baseline. This hypothesis should thus be investigated in further studies.

Many public health facilities across the globe have struggled to provide medical resources to patients, including the most basic oxygen therapy. ${ }^{28,29}$ The World Health Organization recently published guidance urging health facility administrators and decision-makers to set up a surge oxygen delivery capacity. ${ }^{30}$ Enabling physicians to deliver the required oxygen to patients is critical because management of hypoxemia is the cornerstone of COVID-19 patient management. This study demonstrated that both the surgical facemask and the doubletrunk mask have the potential to save a limited resource that is currently in high demand. Settings where oxygen supplies remain limited may benefit most from these systems, such as in nursing homes, health care centers in deprived medical areas, or during patient transport. In our opinion, the double-trunk mask (patent-free) should be favored over the surgical facemask, regardless of the nasal cannula oxygen flow, because of the more favorable blood oxygen level response with the double-trunk mask. The components of the double-trunk mask (aerosol mask and tubes) cost between 2 and $5 €$ and, depending on available resources, can be replaced or reused after daily cleaning (disinfection and rinsing as for reusable nebulizers). If the double-trunk mask disposables (which are for single-patient use only) are not available, or if the cost is an issue, the surgical facemask is an interesting approach in patients needing at least $5 \mathrm{~L} / \mathrm{min}$ of oxygen flow through the nasal cannula.

\section{LIMITATIONS}

First, our study was not powered to assess oxygen savings with each system. However, the large effect size observed in this secondary outcome combined with the strong relationship observed between the $\mathrm{PaO}_{2}$ improvement and the relative 
oxygen flow reduction supports our findings. Moreover, although patients were properly randomized and no statistical differences in baseline characteristics are observed between groups, we cannot rule out the possibility that some heterogeneity occurred between study groups. Second, we did not estimate the long-term tolerance or efficacy of these masks for longer periods than $60 \mathrm{~min}$. However, since the doubletrunk mask has been integrated in our hospital in a step-bystep oxygenation algorithm for hospitalized COVID-19 patients, this mask was found to be well tolerated by patients despite wearing it for days or even weeks. Third, our trial focused on the effect of each system on short-term oxygenation and vital parameters. We are thus unable to determine the role of the intervention in reducing the relative risk of intensive care unit admission.

\section{CONCLUSIONS}

We showed that the addition of the surgical facemask or the double-trunk mask on top of the nasal cannula increases arterial oxygenation and reduces oxygen supplies.

Supplementary Information The online version contains supplementary material available at https://doi.org/10.1007/s11606-02207419-2.

Acknowledgements: Contributors: We are grateful to the medical and nursing staff of the COVID-dedicated wards for their kind assistance in this study.

Sources of support: No funding was received for this study. Gregory Reychler and William Poncin received a grant from the Institut de Recherche Expérimentale et Clinique (Université catholique de Louvain - Brussels - Belgium).

Corresponding Author: William Poncin, PhD; Service de Pneumologie, Cliniques universitaires Saint-Luc, Avenue Hippocrate 10, 1200Brussels, Belgium (e-mail: william.poncin@uclouvain.be).

\section{Declarations:}

Conflict of Interest: The authors declare that they do not have a conflict of interest.

\section{REFERENCES}

1. Wu Z, McGoogan JM. Characteristics of and Important Lessons From the Coronavirus Disease 2019 (COVID-19) Outbreak in China: Summary of a Report of 72314 Cases From the Chinese Center for Disease Control and Prevention. JAMA. 2020;323(13): 1239-1242.

2. Richardson S, Hirsch JS, Narasimhan M, et al. Presenting Characteristics, Comorbidities, and Outcomes Among 5700 Patients Hospitalized With COVID-19 in the New York City Area. JAMA. 2020;323(20):20522059 .

3. Huang $\mathrm{C}$, Wang $\mathrm{Y}$, Li X, et al. Clinical features of patients infected with 2019 novel coronavirus in Wuhan, China. Lancet. 2020;395(10223):497506.

4. Daher A, Balfanz P, Aetou M, et al. Clinical course of COVID-19 patients needing supplemental oxygen outside the intensive care unit. Sci Rep. 2021;11(1):2256

5. Eastwood G, Gardner A, O'Connell B. Low-flow oxygen therapy: selecting the right device. Aust Nurs J. 2007;15(4):27-30.
6. Hardavella G, Karampinis I, Frille A, Sreter K, Rousalova I. Oxygen devices and delivery systems. Breathe (Sheff). 2019;15(3):e108-e116.

7. Poncin W, Baudet L, Reychler G, et al. Impact of an Improvised System on Preserving Oxygen Supplies in Patients With COVID-19. Arch Bronconeumol. 2021;57:77-79.

8. Ottestad W, Søvik S. COVID-19 patients with respiratory failure: what can we learn from aviation medicine? Br J Anaesth. 2020:S00070912(0020)30226-30229.

9. Fontanari P, Burnet H, Zattara-Hartmann MC, Jammes Y. Changes in airway resistance induced by nasal inhalation of cold dry, dry, or moist air in normal individuals. J Appl Physiol (1985). 1996;81(4): 1739-1743.

10. Dell'Era V, Dosdegani R, Valletti PA, Garzaro M. Epistaxis in hospitalized patients with COVID-19. J Int Med Res. 2020;48(8):300060520951040.

11. Xie J, Covassin N, Fan Z, et al. Association Between Hypoxemia and Mortality in Patients With COVID-19. Mayo Clin Proc. 2020;95(6):11381147.

12. Meara JG, Leather AJ, Hagander L, et al. Global Surgery 2030: evidence and solutions for achieving health, welfare, and economic development. Lancet. 2015;386(9993):569-624.

13. India's COVID-19 emergency. The Lancet. 2021;397(10286):1683.

14. Smith L, Baker T, Demombynes G, Yadav P. COVID-19 and Oxygen: Selecting Supply Options in LMICs that Balance Immediate Needs with Long-Term Cost-Effectiveness. Center for Global Development. 2020; https://www.cgdev.org/publication/covid-19-and-oxygen-selecting-supply-options-lmics-balance-immediate-needs-long-term.

15. Trabucchi M, De Leo D. Nursing homes or besieged castles: COVID-19 in northern Italy. Lancet Psychiatry. 2020;7(5):387-388.

16. Duprez F, Bruyneel A, Machayekhi S, et al. The Double-Trunk Mask Improves Oxygenation During High-Flow Nasal Cannula Therapy for Acute Hypoxemic Respiratory Failure. Respir Care. 2019;64(8):908-914.

17. Duprez F, Cocu S, Legrand A, et al. Improvement of arterial oxygenation using the double trunk mask above low flow nasal cannula: a pilot study. $J$ Clin Monit Comput. 2021;35(1):213-216.

18. Wittebole X, Duprez F, Montiel V. Administration of Supplemental Oxygen. $N$ Engl $J$ Med. 2021;385(17):e61.

19. Montiel V, Robert A, Robert A, et al. Surgical mask on top of high-flow nasal cannula improves oxygenation in critically ill COVID-19 patients with hypoxemic respiratory failure. Ann Intensive Care. 2020;10(1): 125.

20. Farias E, Rudski L, Zidulka A. Delivery of high inspired oxygen by face mask. J Crit Care. 1991;6(3):119-124.

21. Hnatiuk OW, Moores LK, Thompson JC, Jones MD. Delivery of high concentrations of inspired oxygen via Tusk mask. Crit Care Med. 1998;26(6): 1032-1035.

22. Chechani V, Scott G, Burnham B, Knight L. Modification of an aerosol mask to provide high concentrations of oxygen in the inspired air. Comparison to a nonrebreathing mask. Chest. 1991;100(6):1582-1585.

23. Saatci E, Miller DM, Stell IM, Lee KC, Moxham J. Dynamic dead space in face masks used with noninvasive ventilators: a lung model study. Eur Respir J. 2004;23(1):129-135.

24. Fraticelli AT, Lellouche F, L'Her E, Taille S, Mancebo J, Brochard L. Physiological effects of different interfaces during noninvasive ventilation for acute respiratory failure. Crit Care Med. 2009;37(3):939-945.

25. Elliott MW. The interface: crucial for successful noninvasive ventilation. Eur Respir J. 2004;23(1):7-8.

26. Roberge RJ, Kim JH, Coca A. Protective Facemask Impact on Human Thermoregulation: An Overview. The Annals of Occupational Hygiene. 2011;56(1):102-112.

27. Lundberg JON, Weitzberg E. Nasal nitric oxide in man. Thorax. 1999;54(10):947-952.

28. Reddy KS. Pandemic lessons from India. BMJ. 2021:n1196.

29. World Health Organization. COVID-19 oxygen emergency impacting more than half a million people in low- and middle-income countries every day, as demand surges. https://www.who.int/news/item/25-02-2021-covid19-oxygen-emergency-impacting-more-than-half-a-million-people-inlow\%2D\%2Dand-middle-income-countries-every-day-as-demandsurges.

30. World Health Organization. Oxygen sources and distribution for COVID19 treatment centres. https://apps.who.int/iris/bitstream/handle/ 10665/331746/WHO-2019-nCoV-Oxygen_sources-2020.1-eng.pdf? sequence $=1$ \&isAllowed $=\mathrm{y}$.

Publisher's Note: Springer Nature remains neutral with regard to jurisdictional claims in published maps and institutional affiliations. 